\title{
Cost-Oriented Strategic Manufacturing and Quality Planning for BPR
}

I. Mezgár

Computer and Automation Research Institute, 1111 Budapest, Kende u. 13-17. Hungary,

Phone:36-1-1811143, Fax:36-1-1667503, E-mail: mezgar@sztaki.hu

C. Basnet and L. R. Foulds

The Univ. of Waikato, Private Bag3105, Hamilton, New Zealand, Phone:64-7-8384562, Fax:64-7-8384270, E-mail:chuda@waikato.ac.nz

\begin{abstract}
The different manufacturing strategies can influence production to a significant extent and, through this, manufacturing process and product quality. A stochastic simulation-based approach has been developed and carried out for estimating product quality on strategic level. The methodology is based on the Taguchi method, and consists of a simulation of the manufacturing system with a view to identifying manufacturing strategies that are relatively insensitive to process fluctuations and are cost effective. The experimental analysis is carried out with the strategies as controllable factors, and process fluctuations as noise factors. The response variable of the experiment is the unit cost of the finished product. While the Taguchi method is usually applied to the tactical design of production systems, we have shown how it can be applied to the strategic design and analysis of manufacturing systems. This approach can help the Business Process Reengineering (BPR) as well.
\end{abstract}

\section{Keywords}

Cost reduction, manufacturing management strategies, product quality, simulation, Taguchi method. 


\section{INTRODUCTION}

Traditional manufacturing has focused on a low cost strategy to capture the market, and consequently, to improve the bottom line. The techniques of flow design, work design, and automation have been the traditional mainstay in accomplishing this strategy. Recently, competitive pressures have pushed quality to the centre stage of manufacturing management. Adoption of a quality strategy has entailed worker involvement, statistical process control, just in time, automation etc. The process-oriented, higher level description of manufacturing-, quality-, and management activities can be integrated in the business processes. The reengineering (flexible adaptation to the actual market environment) of these business processes has a key role in the market competition. In designing manufacturing systems with the goal of high quality, we need to adopt quality strategies which can cope with the vagaries of manufacturing such as process variabilities. This does not imply that cost is no longer a consideration in manufacturing. These types of manufacturing systems has to be designed and operated in a way that yield consistently high quality and, which are, at the same time, cost effective.

There are many factors that influence product quality during the product life-cycle. The technical related variables during the design and manufacturing phase can be called as primary factors (e.g. tolerances), but the management-related factors have significant influence on product quality as well. The realisation of both the quality- and manufacturing management strategies need a longer introductory time, and the real results of these technologies will appear only after a longer period.

So, the thorough analysis and selection of the different quality- and manufacturing management strategies have a very important role. The stochastic simulation is a proper tool to do this analysis and evaluation before introducing any quality, or manufacturing management strategies in a manufacturing system. An additional advantage of the preliminary analysis can be that a robust strategy can be selected by combining the Taguchi methodology with the design of experiment approach. By doing such analysis industrial firms can make more reliable decisions concerning their planned quality assurance and manufacturing strategies without disturbing the actual continuous production. The Taguchi methodology can be applied also in the parallel technical design of products and manufacturing systems as described in Mezgar (1995).

Taguchi has proposed a method of parameter design which provides a means of selecting process parameters which are least sensitive to process variations, i.e., are robust. This process selection is at the tactical level - detailed day to day operation of the manufacturing plant. In this paper we extend the Taguchi method to the strategic design and analysis of a manufacturing system and present a methodology for selecting quality strategies which are robust and cost effective. In evaluating quality strategies, we consider not only the cost of such strategies, but also the benefits (improvement in process capability). This provides a quantitative basis for the selection of quality strategies. The manufacturing strategies of SPC, JIT, and automation are tested in a simulated manufacturing scenario, and their effects on quality costs are investigated. From these, the strategies are evaluated on their robustness from the viewpoint of quality. 


\section{QUALITY-AND MANUFACTURING MANAGEMENT STRATEGIES}

The quality assurance and manufacturing management strategies have a great importance in the market competition especially in economies that are in transient period from any aspect (like in Central Europe as introduced by Foulds and Berka (1992)), or that intends to raise their competitiveness radically (Hyde et.al., 1993). New forms of manufacturing architectures, structures have been developed as well that can give more appropriate answers for the market demands. These strategies are part of the business processes reengineering.

In order to keep their market positions manufacturing enterprises have a strong motivation to move from large, hierarchical organisations to small, decentralised, partly autonomous and co-operative manufacturing units, which can respond quickly to the demands of the customerdriven market. Parallel with these organisational changes the type of production is also changing from mass production techniques to small lots manufacturing. The autonomous production units geographically could be found both inside the enterprise, but outside as well, physically in a long distance. In all of the new forms of the manufacturing organisations different optimal quality- and manufacturing management strategies can be applied.

\subsection{Quality assurance strategies}

The quality of the product is an aggregate of the quality of individual features (geometrical characteristics) and properties (e.g. material). The main difference between traditional and new quality philosophies is that traditional quality approaches focus on correcting mistakes after they have been made while the new philosophies concentrate on preventing failures. For measuring the quality (based on tolerances) the process capability index and the quality loss function can be used. Quality should be designed into the product and into the processes involved when designing, fabricating and maintaining it through its life cycle. Total quality management (TQM) means the continuous satisfaction of user requirements at lowest cost by minimum effort of the company. Taguchi is noted chiefly for his work on designing products and processes with a view to making the quality of the product robust (insensitive) to process or product variations (Taguchi et.al., 1989). His approach have found widespread dissemination and application (e.g. Ross, 1988).

The main reasons why product quality characteristics can deviate from the predetermined values during manufacturing are the inconsistency of material, tool wear, unstable manufacturing process, operator errors, low level system management. In on-line quality control those methods are applied that help to raise the efficiency and stability of the production process (e.g. SPC, diagnosis). In Drucker (1990) the author highlights the role of statistical quality control (SQC) in manufacturing. He sees SQC as improving not only the quality and productivity of an organisation, but also the dignity of labour.

\subsection{Manufacturing management strategies}

The automation which is based on computer technology can give a manufacturing company a big competitive advantage. The different forms and levels (e.g. high-level integrated automation in Computer Integrated Manufacturing Systems vs. balanced automation) of automation needs different manufacturing strategies. 
The human resource management strategy influences all important competitive factors. The education level of the workers, employees can increase/decrease the quality, the time-tomarket as well.

The inventory management strategies has a big influence on cost and on throughput time. The introduction of Just-In-Time (JT), or other strategies need a careful analysis because there is a big financial risk which one to choose.

\section{THE TAGUCHI METHOD}

The methodology for quality control developed by Taguchi et.al.(1989) covers the quality assurance involving both product design and process design stages. Taguchi follows an experimental procedure to set parameters of processes. In Taguchi's method of parameter design, the factors affecting the outcome of a process are separated into controllable factors and noise. factors. Controllable factors are the parameters whose value we seek to determine. Noise factors are factors which cause variation in the response variable, but are normally not amenable to control (but they are controlled for the sake of the experiment). Treatment combinations for controllable factors are set by an experimental design called the inner array, treatment combinations for noise factors are called the outer array. Usually, to save cost and time, a fractional design is used for these arrays, where there are three controllable factors and three noise factors. The controllable factors are set in a full factorial design, but the noise factors are set in an L4 array. Usually, an analysis of variance is not the object of Taguchistyle experiment. The object is to identify the set of parameter values that is most robust to the variations in the noise factors. Taguchi proposes a measure called Signal to Noise $(S / N)$ Ratio. When the response variable is such that a lower value is desirable, one measure of $S / N$ ratio is:

$$
\text { S/ N Ratio }=-10 \log _{10}\left(\frac{1}{n}\right)
$$

where $y_{i}$ is the response variable, and there are $n$ observations in a run. A high value of $\mathrm{S} / \mathrm{N}$ ratio indicates that the corresponding combination of controllable factors is robust.

\section{STRATEGIC DESIGN AND ANALYSIS OF MANUFACTURING SYSTEM}

With the development of modern simulation languages, simulation has established its place in the design of manufacturing systems. Simulation permits modelling of manufacturing systems at any desired level of detail. Controlled experiments can be carried out on a simulated environment at a low cost.

We suggest the use of this environment for the selection of manufacturing strategies following the Taguchi method for manufacturing systems both under design and in operation. The effect of these strategies on the quality levels can be modelled, and experimented upon. For example, the continuous improvement aspect of JT can be modelled by using a learning curve model. The Taguchi method permits us to select robust strategies. An application of this simulation methodology is presented next. 


\subsection{Selecting performance measure and define the target}

The goal of the experiment was to identify levels of the manufacturing strategies which were most robust to quality problems. We used cost per unit of good finished product as the surrogate for the cost effective quality level achieved by the manufacturing system. Consequently, this cost was the response variable. The analysis gave an answer that on what levels of the noise factors were the production cost on minimum while the selected management strategies (factors) are the most insensitive on the noise in the given manufacturing system.

\subsection{Identify factors}

The controllable factors are the manufacturing strategies that we wish to investigate. The three strategies and their levels are (a full factorial design is used for these factors):

1. Statistical process control (Yes $/$ No)

2. Automation (Yes $/$ No)

3. JT learning (Yes/No)

The noise factors that cause variation in the quality of the product and their levels are:

1. Nominal process capability of the processes (Higher/Lower)

2. Complexity - number of serial processes (Low / High)

3. Process shift (Low/High)

All the factors are at two levels. An L4 design is used for the noise factors.

\subsection{Conduct experiment}

A simulated environment of a manufacturing system was created using the simulation language VAX/VMS SIMSCRIPT II.5. (introduced e.g. in User's Manual, 1989). The following assumptions apply to the system. It comprises a number of serial processes. All the processes work to their nominal process capability. The processes are liable to a process shift which causes the process capability to decrease. The distribution of the interval (number of parts) between process shifts is Poisson. However, if nothing is done to the shifted process, it will reset to the nominal capability after another interval, which has the same distribution. There is a nominal cost of processing for each part. After all the operations (serial) are carried out, the quality of the part is checked against the upper (USL) and the lower (LSL) specification limits for all the processes, and if any measurement is out of specification, the product is scrapped.

Three quality strategies are considered: statistical process control (SPC), just-in-time (JT), and automation. When SPC strategy is adopted, samples of size $n$ are taken at an interval of $f$ parts. Upper and lower control limits (UCL and LCL) are calculated on the basis of 3 sigma, and if the process is found out of control, the process is reset to the nominal process capability. There is an additional cost (Cspc) of manufacturing, attributable to the adoption of SPC.

As pointed out earlier, many benefits of automation strategy have been identified in the literature. As far as the quality of the product is concerned, the adoption of automation strategy results in an increase in the process capability. There is an additional cost (Cauto) per part associated with this strategy. 
Similarly, the advocates of JT have claimed many advantages for this strategy. It is agreed that JT is both a philosophy and a discipline which results in a continuous improvement of the processes of a manufacturing organisation. In our simulated environment, the adoption of JT causes the process capability to increase over time, following a learning curve . Again, there is an additional cost (Cjit) incurred for each part. Some of the parameters and their values which were applied during the investigation of the manufacturing strategies are the following:

Nominal process capability: 0.9 (high) and 0.8 (low)

Amount of process shift: 0.4 (high) and 0.3 (low). When the process shifts, the process capability decreases by this amount.

SPC cost Cspc (additional to the nominal cost of \$1): $\$ 0.15$

Increase in the process capability due to automation: 0.2

Automation cost Cauto (additional to other costs): $\$ 0.20$

Learning curve under JT (percentage): $99.5 \%$. Doubling of the number of products causes $99.5 \%$ increase in process capability. JIT cost Cjit(additional to other costs): 0.1

\subsection{Analyse Results and Select Manufacturing Strategy}

The Taguchi method and inside this the $\mathrm{S} / \mathrm{N}$ ratio formula for the smaller-is-better has been used since the goal of the experiment was to minimise cost. The result of the simulation experiment is shown in Table 1 .

Table 1. Results of the Experiment

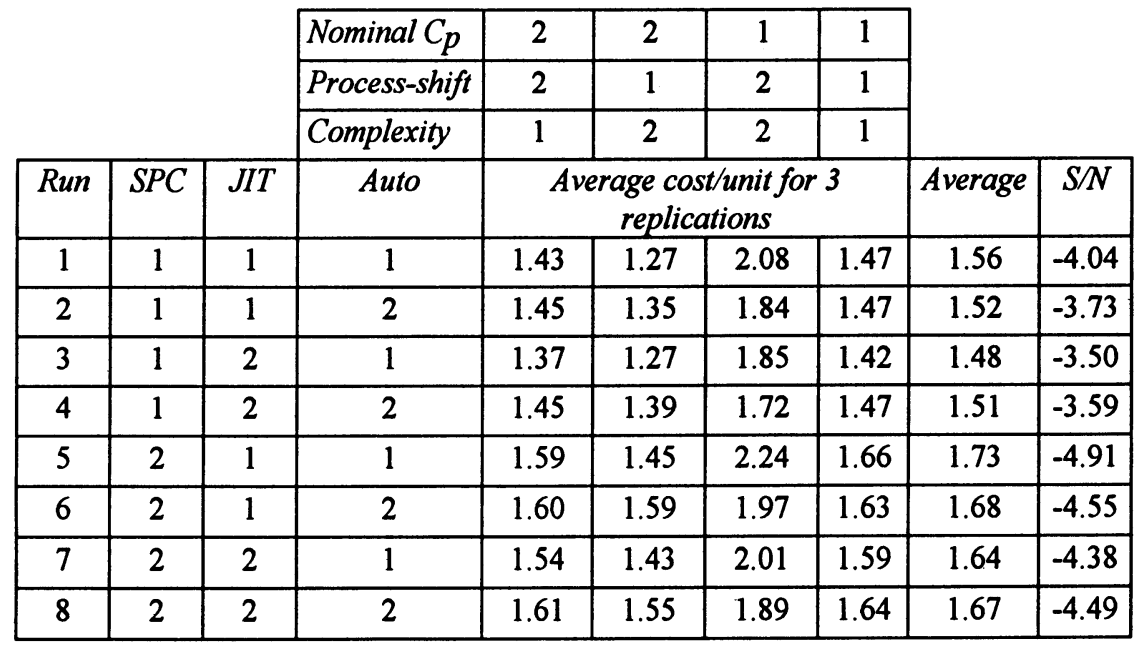




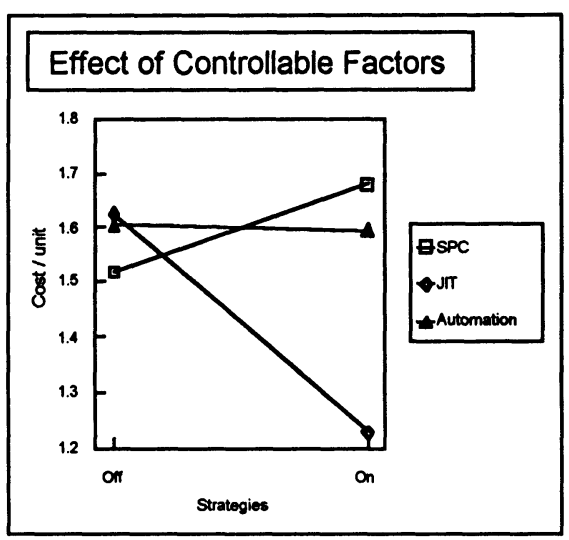

Figure 1. Main Effects of Controllable Factors.
From this table, it can be seen that the most robust strategy for this scenario is the use of JIT, without the adoption of SPC and automation strategies. This gives the lowest average cost per unit of $\$ 1.48$, and the highest S/N Ratio of -3.50 . The main effects of the controllable factors are shown graphically in Figure 1. Obviously, JT has a profoundly desirable effect on quality measured as cost per good units. The effect of automation is to decrease the cost only slightly, while the use of SPC strategy increases costs.

\section{CONCLUSIONS}

We have presented a methodology for the selection of manufacturing strategies. This methodology is based on the Taguchi's method of parameter design and takes into account the current process capability, possible process shifts, the complexity of the existing processes, and the costs and the benefits of the proposed strategies. The methodology was demonstrated on an example hypothetical manufacturing system.

The Taguchi method is normally applied to the tactical design of the production system. Our methodology presents an application of the method to the strategic design or analysis of manufacturing systems. This methodology is extendable to include other manufacturing strategies such as total quality control and supplier certification. The methodology also can be used to analyse the different subprocesses of business processes during reengineering. As a result of using the methodology the firms (mainly little firms - SMEs) can adapt themselves easier, quicker and with less risk to the fast changing market demands by changing their production strategies and process \& product quality levels.

\section{ACKNOWLEDGEMENTS}

The first author is grateful for the Academic Research Visitors Grant that he received from the School Research Committee of the University of Waikato, which made it possible for him to carry out the work. 


\section{REFERENCES}

Drucker, P.F. (1990) The Emerging Theory of Manufacturing, Harvard Business Review, May-June, 1990, 94-102.

Foulds, L.R. and Berka, P.(1992) The achievement of World Class manufacturing in Central Europe, In Proc. of the IFORS SPC-2 Conference on "Transition to Advanced Market Economies", June 22-25, 1992, Warsaw, Eds.: Owsinski, J.W., Stefanski, J., Strasyak, A., pp139-145.

Hyde, A., Basnet, C., Foulds, L.R. (1993) Achievement of world Class Manufacturing in new Zealand: Current Status and Future Prospects, In Proc. of the Conference on "NZ Strategic Management Educators", Hamilton, New Zealand, NZ Strategic Management Society Inc., pp.168-175.

Mezgar, I.(1995) Parallel quality control in manufacturing system design, in the Proc. of Int.

Conf. of Industrial Engineering and Production Management, April 4-7., 1995. Marrakech, Morocco, Eds. IEPM-FUCAM, pp. 116-125.

Ross, P.J. (1988) Taguchi Techniques for Quality Engineering, McGraw-Hill Book Comp., New York-Auckland.

Taguchi, G., Elsayed, E., Hsiang, T.C. (1989) Quality Engineering In Production Systems, McGraw-Hill Book Company, New York.

VAX/VMS SIMSCRIPT II.5 User's Manual, (1989) Release 5.1, CACI Products Company, February 1989.

\section{BIOGRAPHY}

István Mezgár [Diploma in m.e.: 1977, special Diploma in automation engineering: 1988, dr.Univ in m.e.: 1990, all from the Technical University of Budapest (TU), C.Sc. in m.e.: 1995, from the Hungarian Academy of Sciences] is a senior researcher at the CIM Research Laboratory, CARI, HAS. Visiting researcher/professor at the University of Trento, at the University of Genoa (Italy, in 1989-91), at the University of Waikato (New Zealand, in 1995), and at the $C A D / C A M$ Research Laboratory, Korea Institute of Science and Technology (South-Korea, in 1995-96). IPC member of several international IFAC, IFIP conferences. More than 70 scientific publications. His current interests focus on manufacturing automation, integration of product and enterprise models, agile manufacturing systems, design methodologies (e.g. concurrent engineering) and complex quality control. 